\title{
Iniciando un período
}

\author{
Initiating a period
}

Al asumir la Presidencia de la Sociedad de Cirujanos de Chile, adquirí una gran responsabilidad y el compromiso de guiar los destinos de la misma durante el próximo periodo. La permanencia en este cargo por 2 años nos entrega una excelente oportunidad de emprender importantes tareas, que vayan más allá de la realización de un congreso. Afortunadamente no estoy solo en esta tarea. Me acompaña un Directorio de excelencia, encabezado por el vicepresidente Dr. Eduardo Coddou, quien, junto al resto de sus miembros, tiene el compromiso de avanzar para realizar las tareas planteadas.

Desde hace tiempo que se hace patente que nuestra Sociedad requiere cambios. Sin embargo, la tarea de realizarlos, que es una responsabilidad compartida, no ha sido asumida con un compromiso que involucre a todos nuestros socios.

Soy un convencido que a cada Presidente y su Directorio, le corresponden diferentes tareas que debe afrontar de acuerdo a los tiempos y no sería justo extrapolar las actuales necesidades de nuestra Sociedad, a las que hubo en periodos anteriores. Hago un reconocimiento a todos aquellos que me precedieron y que nos permiten enfrentar los nuevos desafios con una Sociedad saneada en lo económico, con nuevos estatutos, con importantes actividades de sus Departamentos y con una Revista que día a día mejora en calidad y cobertura.

Hemos asumido la Presidencia después de un proceso electoral sin precedentes que, basado en los nuevos estatutos, permitió la presentación de candidatos con proyectos y planes de desarrollo objetivos y sobre los cuales deberemos rendir cuentas al finalizar nuestro período.

A través de estas páginas vamos a señalar los aspectos más relevantes de dicho programa. Lo primero es hacer un diagnóstico de la realidad que viven los cirujanos de nuestro país. Realizaremos una encuesta a nuestros miembros, proceso que ya está en ejecución, para saber las características del desempeño profesional en el ámbito tanto público como privado y de acuerdo a la distribución etaria de nuestros socios. ¿Tenemos las condiciones necesarias para una práctica quirúrgica segura, que realmente beneficie a nuestros pacientes? ¿Se dan las posibilidades reales de perfeccionamiento para nuestros médicos más jóvenes? ¿Se involucra el empleador en el desarrollo profesional de sus cirujanos? Esto entre muchos otros temas de gran trascendencia, que nos permitirán definir estándares para el desempeño de la cirugía, de manera de velar por un entorno laboral que permita una práctica profesional segura, acorde a los requerimientos de nuestros pacientes y de nuestros socios.

Debemos reconocer que cuesta hacer participar a nuestros miembros en las actividades de la Sociedad. ¿Cuáles son las causas de este desinterés? Probablemente muchas, pero la que se repite con mayor frecuencia es que nuestra Sociedad no los representa o que no responde a sus inquietudes. Consideramos que es el momento de efectuar cambios importantes que incorporen a los más jóvenes y a los que se consideran marginados, reflejando nuestro interés en hacer de la SCCH un grupo fuerte y representativo, que tenga una importante voz en el ámbito nacional.

Dentro de los objetivos planteados está el incrementar la presencia de cirujanos de regiones, de centros privados, públicos o institucionales más pequeños, en las actividades académicas y científicas, sin disminuir el tradicional aporte de los grandes centros universitarios, hospitales y clínicas.

Deseamos potenciar el Comité Cientifico con reuniones periódicas de planificación que permitan revisar las pautas de aceptación de trabajos para los congresos, de entrega de premios, sugerencias para la revista y toda la actividad cientifica de la Sociedad. 
La labor de los Departamentos ha sido fundamental en el desarrollo cientifico y actualización en las diferentes áreas de la cirugía. Para ello es importante incrementar el rol de éstos a través de reuniones periódicas de los diferentes departamentos con el Presidente y/o Directorio, programando la elaboración de guías de patologías prevalentes, sumado a actividades cientificas y académicas que permanezcan en el tiempo y que representen las diferentes realidades de los centros hospitalarios del país.

Hay áreas relevantes de la cirugía que no están suficientemente representadas en las actividades societarias, es por ello que deseamos crear los departamentos de cirugía endoscópica y de cirugía esófago-gástrica.

La página web, en nuestra concepción, debe ser un vínculo permanente y actualizado entre la Sociedad y sus miembros. Vamos a potenciar su rol, a través de programas web, con actualizaciones de temas y boletines periódicos, haciéndolo amigable y atractivo.

Los cirujanos en formación y aquellos que recientemente han finalizado su perído de especialización deben ser un foco de permanente atención, que permitan proyectar nuestra Sociedad hacia el futuro. Vamos a crear nuevos espacios de desarrollo y participación para residentes de cirugía y cirujanos jóvenes, acogiendo sus inquietudes.

El cambio de estatutos, que elimina las tradicionales "carreras largas y cortas", permite la presentación de listas de candidatos, que presenten programas para ser evaluados por la Asamblea. De esta forma ya no se vota por una persona sino que por un proyecto a desarrollar durante su periodo de gestión. Ojalá en el futuro próximo se presenten varias listas para hacer más competitivo y enriquecedor el proceso eleccionario y el debate que lo acompaña. Hemos detectado que hace falta un reglamento de elecciones, que implementaremos en este periodo permitiendo que éstas sean lo más informadas y transparentes posible.

También debemos enfrentar el Congreso Panamericano de Trauma, aceptado y gestionado desde el periodo presidencial que me antecedió y que se realizará por primera vez en nuestro país en noviembre de este año. Esta vez, por razones logísticas, se hará en la ciudad de Santiago. Nos visitarán destacados especialistas de diferentes países. Si bien el congreso estará centrado en temas de trauma, habrá un espacio importante, como siempre, para realizar las presentaciones clínicas de trabajos, por especialidad. Hacemos un llamado a asistir y a presentar nuestras experiencias clínicas en tan importante instancia.

Personalmente siempre he concebido los congresos como eventos cientificos sociales. Aprovechemos esta oportunidad para participar y compartir.

Deseamos hacer un llamado a enviar para publicación en nuestra Revista, nuestros mejores trabajos de investigación, Ella, día a día ha aumentado su presencia en el ámbito científico nacional e internacional. Debemos celebrar la reciente invitación de EBSCO Publishing para su inclusión en dicha importante base de publicaciones de categoría mundial, lo que sin duda le dará mayor visibilidad y prestigio.

Nos esperan estos desafios y muchos otros. Vislumbremos una Sociedad moderna, activa, llena de actividades, con importante presencia nacional e internacional, que se adapte a los tiempos y que deje una línea de trabajo para las generaciones futuras.

Deseo terminar estas páginas, sellando el compromiso del Directorio que presido, con nuestra Sociedad y con ustedes. Haremos nuestro mejor esfuerzo para cumplir las metas planteadas.

Esperamos su colaboración.

\author{
Dr. Mario Uribe Maturana \\ Presidente Sociedad de Cirujanos de Chile
}

